\section{Total Synthesis of Quercetin 3-Sophorotrioside}

\author{
Yuguo Du, ${ }^{*}+{ }^{\dagger}$ Guohua Wei, ${ }^{\dagger}$ and Robert J . Linhardt*,, \\ Research Center for Eco-Environmental Sciences, \\ Chinese Academy of Sciences, 100085 Beijing, China, and \\ Departments of Chemistry and Chemical Biology, Biology, \\ and Chemical and Biological Engineering, Rensselaer \\ Polytechnic Institute, Troy, New York 12180
}

ygdu2001j@yahoo.com; linhar@rpi.edu

Received November 24, 2003

\begin{abstract}
Dihydroxy-3-[ $\beta$-D-glucopyranosyl-(1 $\rightarrow 2)-\beta$-Dglucopyranosyl-(1 $\rightarrow 2)$ - $\beta$-D-glucopyranosyl ]-2-(3,4-dihydroxyphenyl)-4H-1-benzopyran-4-one (quercetin 3-sophorotrioside), a flavonol triglycoside, isolated from Pisum sativum shoots and showing protective effects on liver injury induced by chemicals, was synthesized for the first time. The target compound was successfully synthesized in eight linear steps and in 39\% overall yield through a combination of phasetransfer-catalyzed (PTC) quercetin C-3 glycosylation and silver triflate (AgOTf) promoted carbohydrate chain elongation using both sugar bromide and trichloroacetimidate donors.
\end{abstract}

Flavonoid glycosides are widely distributed natural products obtained from fruits, vegetables, and traditional medicinal plants. ${ }^{1}$ They have important biological activities in the growth and development of plants and, more interestingly, are potent drug candidates displaying antimicrobial, anticancer, and antioxidant properties. ${ }^{2}$ Some of these glycosides inhibit xanthine oxidase, which catalyzes the oxidation of xanthine and hypoxanthine to uric acid. They also inhibit the related NADH-oxidase through the involvement of a C2,3 double bond, a C4 keto group, and the $3^{\prime}, 4^{\prime}, 5^{\prime}$-trihydroxy flavonoid. These glycosides may also inhibit the cyclooxygenase and/or the 5-lipoxygenase in arachidonate metabolism and show anti-inflammatory activity. I ndeed, polyphenol-rich diets have been repeatedly advocated to reduce the risk of devel oping cardiovascular diseases and cancers, and some flavonoid glycosides are currently used for the treatment of vascular diseases. ${ }^{3-5}$ Despite the widespread distribution and biological importance of flavonol and other polyphenol glycosides, the efficient glycosylation of phenolic aglycones remains as a difficult task. ${ }^{6-14} \mathrm{~A}$ major challenge in the synthesis of flavonoid glycosides, such as catechin, is their sensitivity to standard Lewis acid catalyzed glycosylation conditions. ${ }^{15,16}$ Furthermore, re gioselective glycosylation, especially multiglycosyl substitution of flavonoids or polyphenols, results in addi-

\footnotetext{
${ }^{\dagger}$ Chinese Academy of Sciences.

₹ Rensselaer Polytechnic Institute.

(1) Bohm, B. A. Introduction to Flavonoids; Harwood Academic Publishers: Amsterdam, 1998.

(2) Harborne, J . B.; Baxter, H. TheHandbook of Natural Flavonoids; J ohn Wiley \& Sons: Chichester, 1999; Vol. 1.

(3) Harborne, J. B.; Williams, C. A. Phytochemistry 2000, 55, 481.

(4) Pietta, P.-G. J . Nat. Prod. 2000, 63, 1035.

(5) Formica, J. V.; Regelson, W. Food Chem. Toxicol. 1995, 33, 1061.
}

tional difficulties including reduced yields and poor stereochemical outcomes. ${ }^{6,17}$

Quercetin 3-sophorotrioside, a flavonol triglycoside (3O- $\beta$-D-glucopyranosyl- $(1 \rightarrow 2)$ - $\beta$-D-glucopyranosyl-( $1 \rightarrow 2$ $\beta$-D-glucopyranoside) isolated from the young seedpods of Pisum sativum, ${ }^{18}$ shows protective effects in liver injury induced in mice with D-galactosamine and Iipopolysaccharide and with carbon tetrachloride. ${ }^{19}$ In the course of these studies on flavonol glycoside synthesis, we show the promise of the phase transfer catalyzed (PTC) glycosylation of quercetin C-3 and report the first total synthesis of quercetin 3-sophorotrioside $\mathbf{1}$.

Quercetin 3-sophorotrioside (1) was retrosynthetically disconnected into two distinct fragments, suitably protected quercetin $\mathbf{2}$ and a glucopyranosyl trisaccharide $\mathbf{3}$ (Scheme 1, path a). Alternatively, 1 might also be synthesized from quercetin $\mathbf{2}$ and monosaccharide donors $\mathbf{5}, \mathbf{6}$, or $\mathbf{7}$ by taking advantage of 2-OAc neighboring participation effects to secure the 1,2-trans glycosylation of each sugar residue (Scheme 1, path b).

Following our previous successful synthesis of calabricoside $A,{ }^{17}$ we initially focused our attention on the convergent synthetic strategy (Scheme 1, path a). Thus, employing a procedure similar to that developed by $\mathrm{J}$ urd, ${ }^{20}$ commercially available quercetin was converted into 7,4'-di-O-benzylated 2 in three steps and in 25\% overall yield, i.e., acetylation of quercetin with acetic anhydride in pyridine; regioselective benzylation of C-7 and $\mathrm{C}-4^{\prime}$ with benzyl chloride and $\mathrm{K}_{2} \mathrm{CO}_{3}$ in refluxing acetone; and deacetylation with $10 \%$ aqueous $\mathrm{NaOH}$. Trisaccharide bromide $\mathbf{3}$ was prepared through conventional glycosylation and functional group manipulation (Scheme 2). To this end, glucopyranosyl trichloroacetimidate $\mathbf{8}^{21}$ was converted into its allyl glycoside $\mathbf{9}$, and the resultant 2-OAc was removed with $5 \%$ acetyl chloride in methanol to give acceptor $\mathbf{1 0}$. Condensation of $\mathbf{8}$ and $\mathbf{1 0}$ in $\mathrm{CH}_{2} \mathrm{Cl}_{2}$ under the promotion of trimethylsilyl trifluoromethanesulfonate (TMSOTf) afforded disaccharide $\mathbf{1 2}$ in $88 \%$ yield. Deacetylation of $\mathbf{1 2}(\rightarrow \mathbf{1 3})$, followed by the

(6) Alluis B.; Dangles, O. Helv. Chim. Acta 2001, 84, 1133.

(7) Vermes, B.; Chari, V. M.; Wagner, H. Helv. Chim. Acta 1981 64,1964

(8) Bouktaib, M.; Atmani, A.; Rolando, C. Tetrahedron Lett. 2002, 43,6263 .

(9) Demetzos, C.; Skaltsounis, A.-L.; Tillequin, F.; Koch, M. Carbohydr. Res. 1990, 207, 131.

(10) Li, M.; Han, X.; Yu, B. Tetrahedron Lett. 2002, 43, 9467.

(11) O'Leary, K. A.; Day, A. J .; Needs, P. W.; Sly, W. S.; O'Brien, N. M.; Williamson, G. FEBS Lett. 2001, 503, 103.

(12) Caldwell, S. T.; Crozier, A.; Hartley, R. C. Tetrahedron 2000 $56,4101$.

(13) Zhang, Z.; Yu, B. J . Org. Chem. 2003, 68, 6309.

(14) Capozzi, G.; Falciani, C.; Menichetti, S.; Nativi, C.; Raffaelli, B. Eur. J . Chem. 1999, 5, 1748.

(15) Brown, R. T.; Carter, N. E.; Mayalarp, S. P.; Sceinmann, F Tetrahedron 2000, 56, 9591.

(16) Cren-Olive, C.; Lebrun, S.; Rolando, C. J . Chem. Soc., Perkin Trans. 1 2002, 821.

(17) Du, Y.; Wei, G.; Linhardt, R. J . Tetrahedron Lett. 2003, 44, 6887.

(18) Ferreres, F.; Esteban, E.; Carpena-Ruiz, R.; J imenez, M. A.; Tomas-Barberan, F. A. Phytochemistry 1995, 39, 1443.

(19) Murakami, T.; Kohno, K.; Ninomiya, K.; Matsuda, H.; Yoshikawa, M. Chem. Pharm. Bull. 2001, 49, 1003.

(20) J urd, L. J . Org. Chem. 1962, 27, 1294. 2289 .

(21) Du, Y.; Zhang, M.; Kong, F.J . Chem. Soc., Perkin Trans. 12001 
SCHEME 1. Retrosynthetic Analysis of Quercetin 3-Sophorotrioside (1)

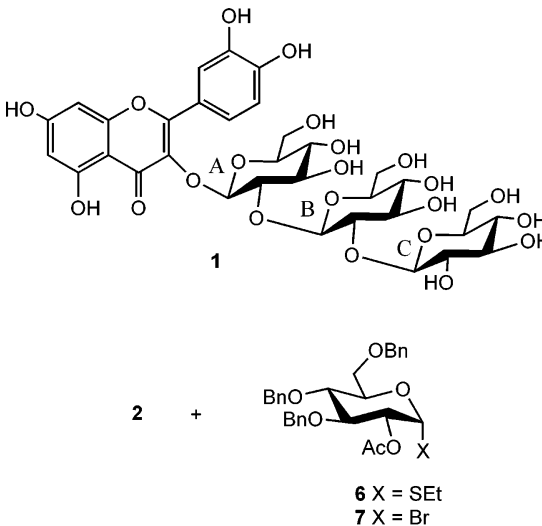

$7 \mathrm{X}=\mathrm{Br}$<smiles></smiles>

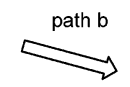

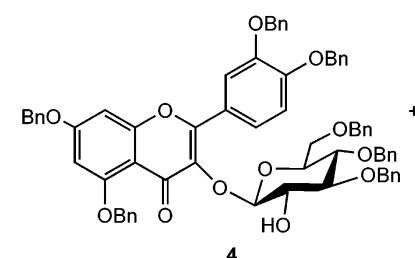

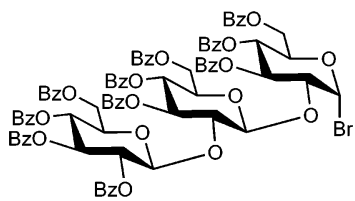

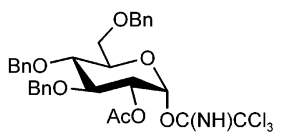

\section{SCHEME 2. Attempted Synthesis Toward to Precursor $17^{a}$}

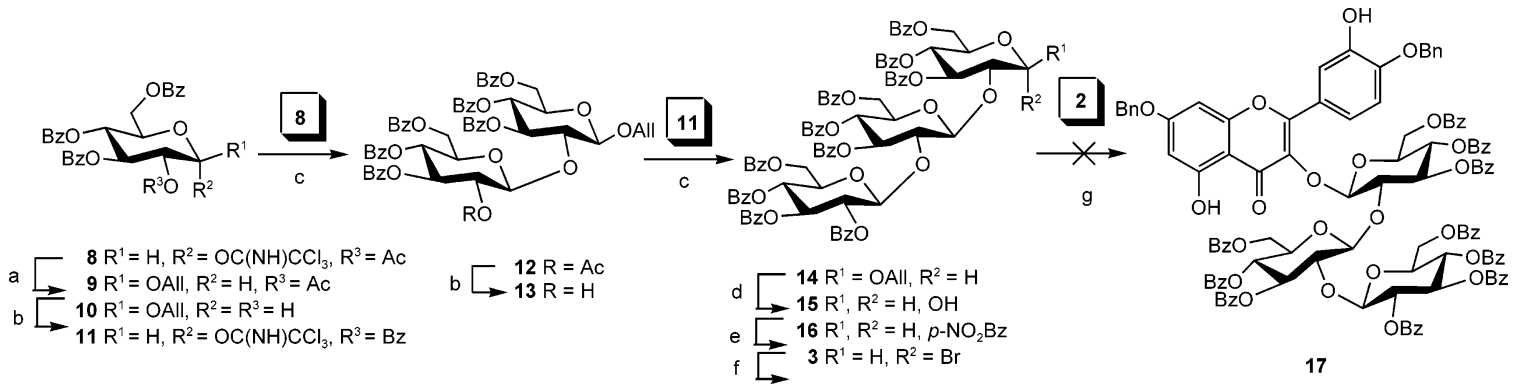

a Reagents and conditions: (a) allyl alcohol, TMSOTf, $\mathrm{CH}_{2} \mathrm{Cl}_{2}, 86 \%$; (b) AcCl, DCM/MeOH (1:1 v/v), 94\% for 10, 54\% for 13; (c) TMSOTf, $\mathrm{CH}_{2} \mathrm{Cl}_{2}, 88 \%$ for 12, 75\% for 14; (d) $\mathrm{PdCl}_{2}, 90 \% \mathrm{HOAC}, \mathrm{NaOAC}, 55 \%$; (e) $\mathrm{p}-\mathrm{NO}_{2} \mathrm{BzCl}, \mathrm{Pyr}, 70 \%$; (f) $\mathrm{HBr}, \mathrm{HOAC}_{\text {; (g) } 0.15 \mathrm{M} \mathrm{aq} \mathrm{K}} \mathrm{CO}_{3}, \mathrm{CHCl}_{3}$, TBAB, $50{ }^{\circ} \mathrm{C}$.

similar glycosylation with donor $\mathbf{1 1}$, gave allyl trisaccharide 14 in $41 \%$ yield over two steps. Removal of the allyl group from 14 was carried out smoothly with $\mathrm{PdCl}_{2}$ in $90 \% \mathrm{HOAc} / \mathrm{NaOAc}$ to give hemiacetal $\mathbf{1 5}$ in $55 \%$ isol ated yiel d. ${ }^{22}$ We next tried to convert $\mathbf{1 5}$ to bromide 3 through acetylation $\left(\mathrm{AC}_{2} \mathrm{O}\right.$ in pyridine) and bromination $(\mathrm{HBr}$ in HOAc). However, bromination proved to be difficult and only a trace amount of $\mathbf{3}$ was produced. To improve the synthesis of 3, hemiacetal $\mathbf{1 5}$ was first transformed into 4-nitrobenzoyl derivative $\mathbf{1 6}$ with 4-nitrobenzoyl chloride in pyridine and then subjected to bromination with $\mathrm{HBr}$ in HOAc. Using this approach, $\mathbf{3}$ was obtained from $\mathbf{1 5}$ in $70 \%$ yield. Unfortunately, PTC ${ }^{23-25}$ coupling reaction of $\mathbf{3}$ and $\mathbf{2}$ under various reaction conditions failed to give the desired structure 17. Instead, decomposition of trisaccharide bromide $\mathbf{3}$ was observed based on TLC analysis.

Quercetin 3-sophorotrioside 1 might also be convergently prepared from its precursor $\mathbf{2 3}$, through the coupling of $\mathbf{4}$ with disaccharide donor $\mathbf{2 2}$. To prepare compound 4, we first attempted to glycosylate the quercetin 3-OH of $\mathbf{2}$ with glucopyranosyl trichloroacetimidate $5^{26}$ based on a similar successful example. ${ }^{27}$ However, all attempts failed, leading instead to complex products,

(22) Du, Y.; Pan, Q.; Kong, F. Synlett 1999, 1648.

(23) J ensen, K. J . J. Chem. Soc., Perkin Trans. 1 2002, 2219 2775.

(24) Hongu, M.; Saito, K.; Tsujihara, K. Synth. Commun. 1999, 29,

(25) Lewis, P.; Kaltia, S.; Wähälä, K. J . Chem. Soc., Perkin Trans. 1 1998, 2481.

(26) Schmidt, R. R.; Effenberger, G. Liebigs Ann. Chem. 1987, 825.

(27) Brown, R. T.; Carter, N. E.; Mayalarp, S. P.; Scheinmann, F. Tetrahedron 2000, 56, 7591 .

\section{SCHEME 3. Synthesis of Key Intermediate $4^{a}$}
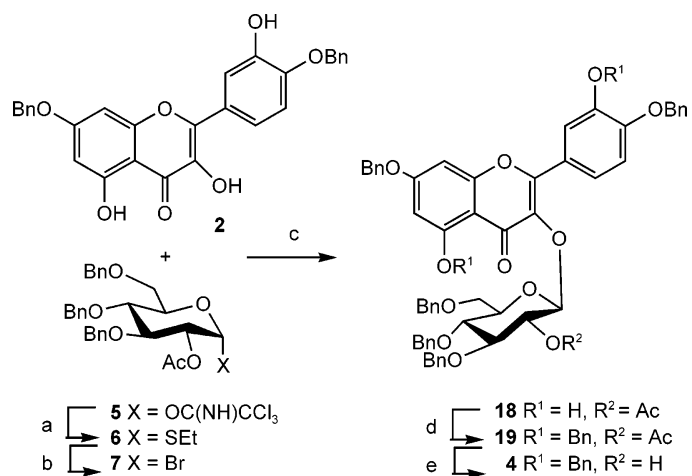

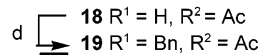

e $\longrightarrow 4 R^{1}=B n, R^{2}=H$

a Reagents and conditions: (a) EtSH, TMSOTf, $\mathrm{CH}_{2} \mathrm{Cl}_{2}, 95 \%$; (b) $\mathrm{Br}_{2}, \mathrm{CH}_{2} \mathrm{Cl}_{2}, 0{ }^{\circ} \mathrm{C}, 100 \%$; (c) $0.15 \mathrm{M}^{\circ}$ a K${ }_{2} \mathrm{CO}_{3}, \mathrm{CHCl}_{3}$, TBAB, $50{ }^{\circ} \mathrm{C}, 90 \%$; (d) $\mathrm{BnBr}, \mathrm{K}_{2} \mathrm{CO}_{3}, \mathrm{DMF}, 93 \%$; (e) $\mathrm{NaOMe}, \mathrm{MeOH}, 86 \%$.

possibly due to decomposition of either $\mathbf{5}$ or the resulting products under the acidic reaction conditions. We next transformed $\mathbf{5}$ into $\mathbf{6}{ }^{28}$ Condensation of compound $\mathbf{6}$ and 2 using known methods ${ }^{29}$ still failed to give the desired product. We finally turned to basic PTC conditions for this glycosylation (Scheme 3). Thioglycoside $\mathbf{6}$ was treated with bromine in $\mathrm{CH}_{2} \mathrm{Cl}_{2}$ at $0{ }^{\circ} \mathrm{C}$ to give bromide 7,30 which was used directly for the next reaction. Partially benzylated bromide $\mathbf{7}$ (1.2 equiv) was condensed with quercetin derivative 2 in $0.15 \mathrm{M} \mathrm{K}_{2} \mathrm{CO}_{3} / \mathrm{CHCl}_{3}$ in the presence of tetrabutylammonium bromide (TBAB) at $50{ }^{\circ} \mathrm{C}$, giving

(28) Garegg, P. J .; Hällgren, C. J . Carbohydr. Chem. 1992, 11, 425.

(29) Toshima, K.; Tatsuta, K. Chem. Rev. 1993, 93, 1503.

(30) Shaban, M. A. E.; J eanl oz, R. W. Carbohydr. Res. 1976, 52, 103. 


\section{SCHEME 4. Second Convergent Synthetic Approacha}

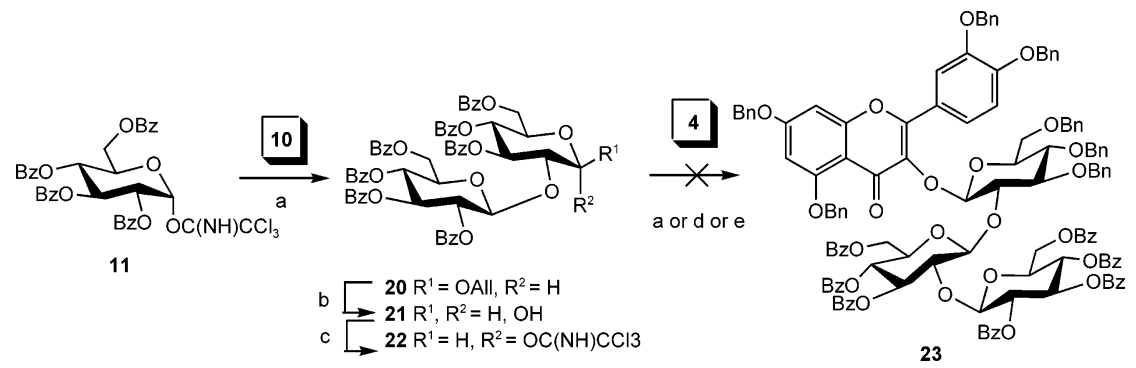

a Reagents and conditions: (a) TMSOTf, $\mathrm{CH}_{2} \mathrm{Cl}_{2}, 90 \%$ for 20; (b) $\mathrm{PdCl}_{2}, 90 \% \mathrm{HOAC}^{\mathrm{NaOAC}}$ (c) $\mathrm{CCl}_{3} \mathrm{CN}, \mathrm{DCM}, \mathrm{DBU}, 50 \%$ from 20; (d) $\mathrm{BF}_{3} \cdot \mathrm{Et}_{2} \mathrm{O}, \mathrm{DCM}$; (e) AgOTf, DCM.

\section{SCHEME 5. Completion of the Total Synthesisa}
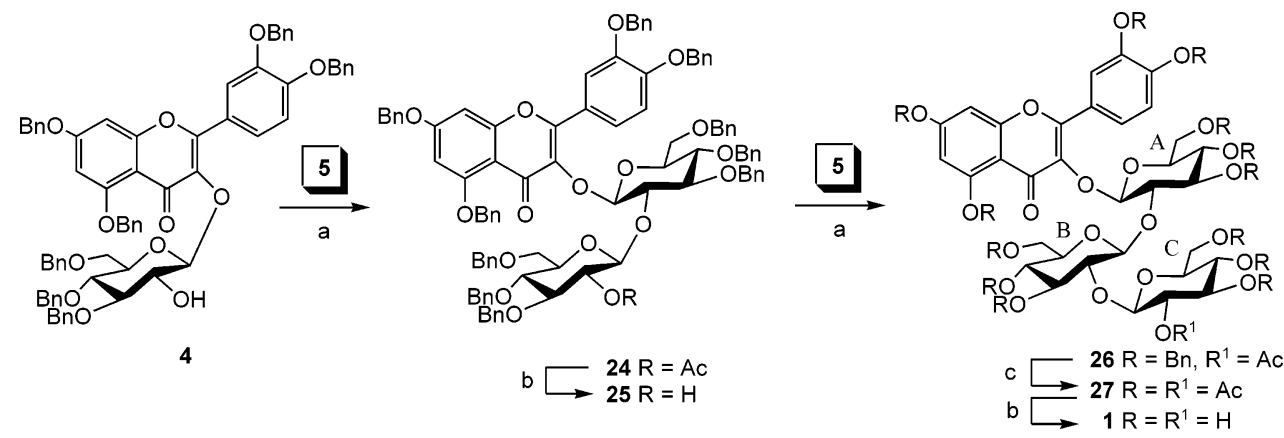

a Reagents and conditions: (a) AgOTf, $\mathrm{CH}_{2} \mathrm{Cl}_{2}, 87 \%$ for 24, 90\% for 26; (b) $\mathrm{NaOMe}, \mathrm{MeOH}, 86 \%$ for 25, 95\% for $\mathbf{1}$; (c) $\mathrm{Pd}(\mathrm{OH})_{2}-\mathrm{C}, \mathrm{H} 2$; $\mathrm{Ac}_{2} \mathrm{O}, \mathrm{Pyr} ; 85 \%$ for two steps.

the C-3 glycosylated compound $\mathbf{1 8}$ in $90 \%$ yield. Proton coupling $(\mathrm{J}=8 \mathrm{~Hz})$ observed for the anomeric proton of glucose residue ( $\delta 5.50 \mathrm{ppm}$ ) demonstrated the expected $\beta$-linkage to the quercetin moiety. The cross-peak from glucosyl H-1 ( $\delta 5.50$ ppm) to quercetin C-3 ( $\delta 135.75$ ppm) in the HMBC spectra confirmed that the glycosylation took place at the $\mathrm{C}-3$ position of the quercetin residue. No $\alpha$-isomer was detected under these glycosylation conditions. Benzylation of the 5,3' hydroxyl groups on $\mathbf{1 8}$ with benzyl bromide and $\mathrm{K}_{2} \mathrm{CO}_{3}$ in $\mathrm{DMF}$ at room temperature furnished 19, which was further treated with $\mathrm{NaOMe}$ in $\mathrm{MeOH}$ to give acceptor 4 in $80 \%$ yield (two steps).

Glycosylation of trichloroacetimidate $\mathbf{1 1}^{31}$ and acceptor $\mathbf{1 0}$ with the promotion of TMSOTf in dry dichloromethane gave disaccharide $\mathbf{2 0}$ in a convergent fashion. Removal of the allyl group from 20 with $\mathrm{PdCl}_{2}$ in a 90\% $\mathrm{HOAC}$ NaOAc system $(\rightarrow \mathbf{2 1})$, followed by imidation (DBU, trichloroacetonitrile), gave trichloroacetimidate 22 in $45 \%$ yield over three steps. Unfortunately, the final condensation between $\mathbf{4}$ and $\mathbf{2 2}$ (Scheme 4) failed to afford the desired product under standard glycosylation conditions using AgOTf, $\mathrm{BF}_{3} \cdot \mathrm{Et}_{2} \mathrm{O}$, and TMSOTf as catalysts. ${ }^{32}$ This condensation also failed under inverse glycosylation conditions. ${ }^{33}$

The unexpected difficulty in the convergent synthesis of $\mathbf{1}$ led us to modify our approach. A simple linear strategy was adopted for the total synthesis of $\mathbf{1}$ (Scheme 5). Silver triflate catalyzed gl ycosylation of trichloroacetimidate 5 and acceptor 4 in $\mathrm{CH}_{2} \mathrm{Cl}_{2}$ at $-30{ }^{\circ} \mathrm{C}$ afforded

(31) He, H.; Yang, F.; Du, Y. Carbohydr. Res. 2002, 337, 1673.

(32) Boons, G.-J . Tetrahedron 1996, 52, 1095.

(33) Schmidt, R. R.; Toepfer, A. Tetrahedron Lett. 1991, 32, 3353. the quercetin disaccharide derivative $\mathbf{2 4}$ in excellent yield. Using TMSOTf or $\mathrm{BF}_{3} \cdot \mathrm{Et}_{2} \mathrm{O}$ as catalysts in place of AgOTf caused the rapid consumption of donor $\mathbf{5}$, making reaction sluggish. Treatment of $\mathbf{2 4}$ with $\mathrm{NaOMe}$ in $\mathrm{MeOH}$ for 2 days at room temperature afforded 25 in $86 \%$ yield. Reiterative coupling of $\mathbf{5}$ with $\mathbf{2 5}$ afforded quercetin trisaccharide $\mathbf{2 6}$ (90\%). Complete removal of the C-2 acetyl group from the glucose residue of trisaccharide $\mathbf{2 6}$ was extremely difficult, taking 7 days under Zemplén conditions. ${ }^{34}$ More practically, deprotection could be accomplished by hydrogenation of $\mathbf{2 6}$ over $20 \%$ $\mathrm{Pd}(\mathrm{OH})_{2}$ on charcoal in ethanol and ethyl acetate (1:1) under normal pressure, followed by full acetylation $\left(\mathrm{Ac}_{2} \mathrm{O}\right.$ in pyridine, $\rightarrow$ 27), silica gel column purification, and final removal of all acetyl groups using a catalytic amount of $\mathrm{NaOMe}$ in methanol, affording quercetin 3-sophorotrioside 1 in $81 \%$ yield over three steps. The diagnostic ${ }^{1} \mathrm{H}$ NMR signals for $\mathbf{1}$ were identical to those reported by Tomas-Barberan et al. in DMSO- $\mathrm{d}_{6}{ }^{18}$ It is worth noting that the attempted coupling reaction of $\mathbf{2 5}$ and $\mathbf{1 1}$ gave ambiguous results as a result of difficulties in obtaining a clean ${ }^{1} \mathrm{H}$ NMR spectra. Rapid decomposition of donor $\mathbf{1 1}$ was also observed under standard glycosylation conditions using Lewis acids as catalysts. In addition, $\mathbf{1}$ was easily oxidized on TLC when exposed to air at room temperature.

We describe here the first total synthesis of quercetin 3-sophorotrioside from 7,4'-di-O-benzyl quercetin in eight steps and 39\% overall yield. PTC glycosylation of quercetin $\mathrm{C}-3$ proved to be very efficient using $0.15 \mathrm{M}$ aqueous $\mathrm{K}_{2} \mathrm{CO}_{3}$ and 1 equiv of TBAB in chloroform at $50{ }^{\circ} \mathrm{C}$ for mono- and disaccharide bromide donors ${ }^{10,17}$ but was not

(34) Du, Y.; Pan, Q.; Kong, F. Carbohydr. Res. 2000, 329, 17. 
suitable for a trisaccharide bromide in this total synthesis. Furthermore, glycosylation of the glucose $2-\mathrm{OH}$ is extremely sensitive to the stereo environment. The " $2+$ 1" strategy was frustrated while a step-by-step glycosylation of the 2-OH groups proceeded smoothly. We also found that AgOTf was a better catalyst than TMSOTf and $\mathrm{BF}_{3} \cdot \mathrm{Et}_{2} \mathrm{O}$ for trichloroacetimidate donors in the preparation of this flavonol glycoside. ${ }^{35}$ The results of the present exploration should be valuable in the preparation of multiglycosylated flavonol glycosides. ${ }^{36-38}$

(35) Wei, G.; Gu, G.; Du, Y. J . Carbohydr. Chem. 2003, 22, 385.

(36) Gunasegaran, R.; Subramani, K.; Parimala, P. A.; Nair, A. G. R.; Rodriguez, B.; Madhusudanan, K. P. Fitoterpia 2001, 72, 201.
Acknowledgment. We thank the NNSF of China (Project 20372081, 30330690) and NIH of the U.S. (HL62244) for supporting of this research.

Supporting Information Available: Experimental procedures and spectral data for compounds 1, 4, 9, 10, 14, 1820, 22, and 24-27. This material is available free of charge via the Internet at http://pubs.acs.org.

J O035722Y

(37) Calis, I.; Kuruüzüm, A.; Demirezer, Ö.; Sticher, O.; Ganci, W.; Rüedi, P. J . Nat. Prod. 1999, 62, 1101.

(38) Calis, I.; Heilmann, J.; Tasdemir, D.; Linden, A.; Ireland, C. M.; Sticher, O. J . Nat. Prod. 2001, 64, 961. 